Vol. 8, Issue 5, May 2019

\title{
Meander Shaped Bandpass Filter With Low Insertion Loss
}

\author{
S.Rajapriya ${ }^{1}$, G.Gomathi ${ }^{2}$, T.Muruganantham ${ }^{3}$ \\ Assistant Professor, Department of ECE, K.Ramakrishnan College of Engineering,Trichy, India ${ }^{1,2,3}$
}

\begin{abstract}
The paper proposes the design of bandpass filter using meander structure. The application in which it can be used includes WLAN applications used for vehicular communication. The feed arrangement used in this structure includes coupled feeding using SIR. The low insertion loss in this structure is achieved by modifying the properties of meander. The dimension of the meander structure and distance between the two meander is adjusted to provide low insertion and return loss. Coupling effect takes place between the meander and SIR to provide output at the ports. Thus insertion loss and return loss are effectively obtained and the structure can be used for WLAN applications.
\end{abstract}

Keywords: Coupling Effect; Inseertion Loss; Meander Structure; Return loss; SIR (stepped impedence resonator), WLAN (Wireless Local Area Network)

\section{I.INTRODUCTION}

In general a CPW fed ring shaped antenna is used for realtimeLAN's [2]. Miniaturization through Negative material effects is proposed in [1], where the monopole antenna operated at WLAN and Wi-max frequencies. It is very compact size due to metamaterial effect by loading the antenna with ELC metamaterial resonator. Similar better impedance matching was achieved to make the antenna resonate efficiently [3,4]. A SRR loaded material antenna is proposed for RF-ID applications. Similarly in [5] a CPW fed antenna with broadside array beam suitable for Wi-Max applications. An optimized coupling network was designed using optimization techniques like ANN [6]. Optimized coupler and power divider was designed using SIW which helped in achieving an optimized response at desired wireless application [7,8,10]. An optimized miniaturized filter using stepped impedance resonators was proposed in [9],to achieve higher selectivity for resonating at the desired frequency. Current innovations on high frequency applications like millimetre wave applications, were discussed in [10] to have a broader view in designing antennas. Using [10], a compact patch antenna was designed for ISM band Application[9].

Apart from all these structures and types, SIR which is known asstepped impedence resonator is used to improve the return loss obtained in bandpass filter. The important property of bandpass filter is to enhance the insertion loss and return loss. Today wireless communication moves towards reducing the size of antennas and filters used in communication devices. Miniaturization is becoming one of the main challenges in today's technology. The achievement of compact size leads to deployment of other characteristics such as data rate, lifetime, etc. These requirements can be met in this project by using meander shaped structure. Meander is a shape which contains a regular series of curves, bends, loops, turns or windings. Meander shaped antennas are electrically small antennas. The design of meander line is a set of horizontal and vertical lines. The combination of horizontal and vertical lines gives the meander shape. The meander shape is shown in Fig 1.

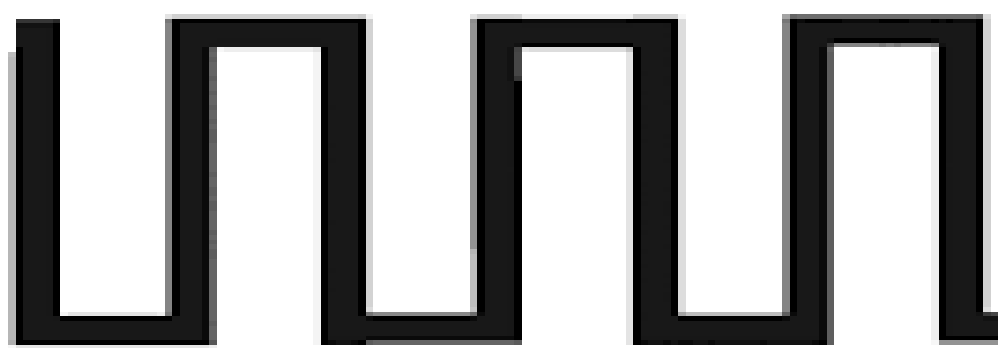

Fig 1 Meander Shape 


\section{International Journal of Advanced Research in Computer and Communication Engineering}

Vol. 8, Issue 5, May 2019

\section{II.MEANDER BASED MICROSTRIP BPF USING SIR}

The meander shaped structure is designed and coupled with stepped impedance resonator. Here four sets of loops are used to form the meander structure. This is done in order to achieve a good response in the band pass filter. The substrate used here is FR-4. The dielectric constant of FR-4 is 4.4. The thickness of the substrate is chosen to be $1.6 \mathrm{~mm}$. The overall substrate size is found to be $(30 \times 51.5) \mathrm{mm}^{2}$.

The plane of the substrate is first divided into two equal halves. The first half consists of a meander coupled with SIR. The SIR acts as a feed for port1. The second half consists of the mirror image of what is described above. The bottom layer consists of the ground plane. The above described structure is simulated by using HFSS software which is shown in Figure 2. The insertion loss and return loss obtained for this structure is found to be $-3.72 \mathrm{~dB}$ and $-21.95 \mathrm{~dB}$ respectively.

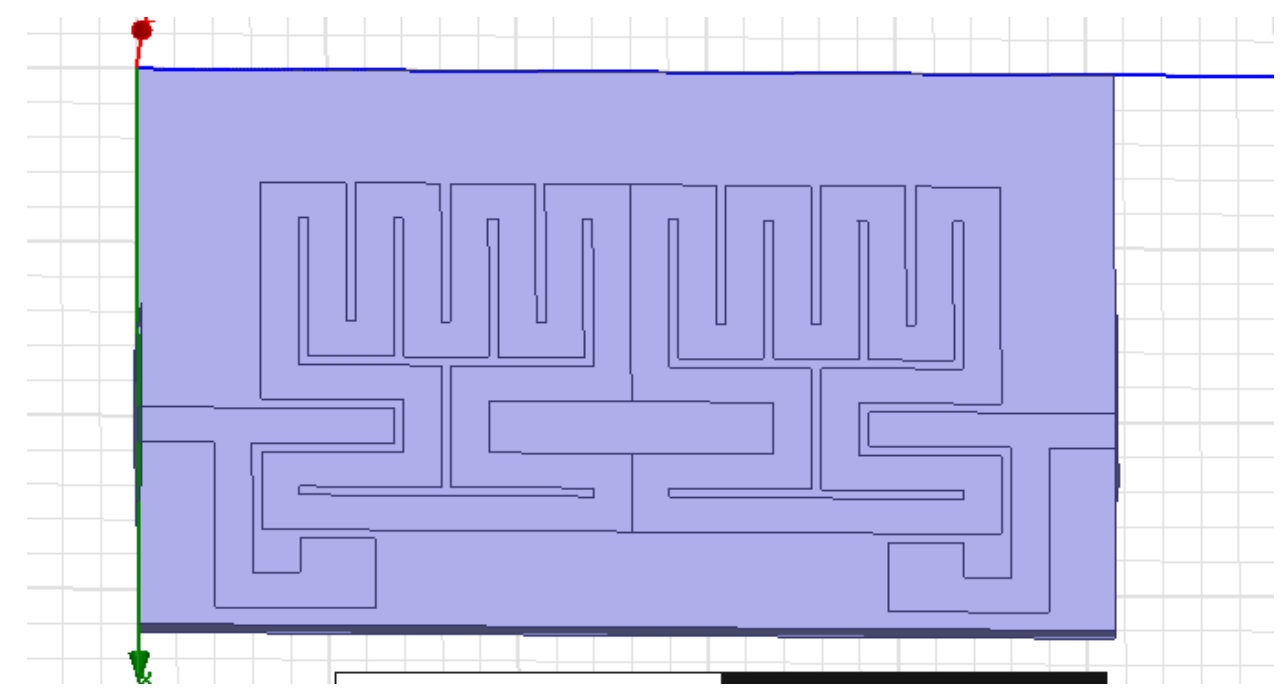

Fig 2 Meander Line Based Microostrip Band Pass Filter

\section{III.GEOMETRY OF PROPOSED FILTER}

The total length of the substrate is $(30 \times 51.5) \mathrm{mm}^{2}$. A total of four loops is used for each meander in order to get the desired results. As mentioned before horizontal and vertical rectangles are used to provide the meander shape. Rectangles are constructed separately and merged to get the shape of meander. The gap between each rectangle in the meander is $0.5 \mathrm{~mm}$. Two meanders are constructed and joined at the center directly without any coupling. The width of each rectangle used is $2 \mathrm{~mm}$.

The length of vertical and horizontal rectangles are found to be $8 \mathrm{~mm}$ and $4.5 \mathrm{~mm}$ respectively . This structure is found to be symmetrical with the top and bottom gaps from the substrate being $5.5 \mathrm{~mm}$ and $1 \mathrm{~mm}$ respectively. The side gaps are found to be $6.25 \mathrm{~mm}$.Stubs are used as feed for the ports 1 and 2 . The width of the stub is also $2 \mathrm{~mm}$. The stub is then converted into an SIR. The length and width of the SIR is $4 \mathrm{~mm}$ respectively. The ports are connected to the stubs. The ports used here are lumped ports. Lumped ports are used in order to get a good response from the filter. The length and width of the ports are $10 \mathrm{~mm}$ and $9.6 \mathrm{~mm}$ respectively.

\section{IV.RESULTS AND DISCUSSION}

The structure of proposed filter described here is done using SIR in HFSS software. The corresponding output for the design is shown in Fig 3 
Vol. 8, Issue 5, May 2019

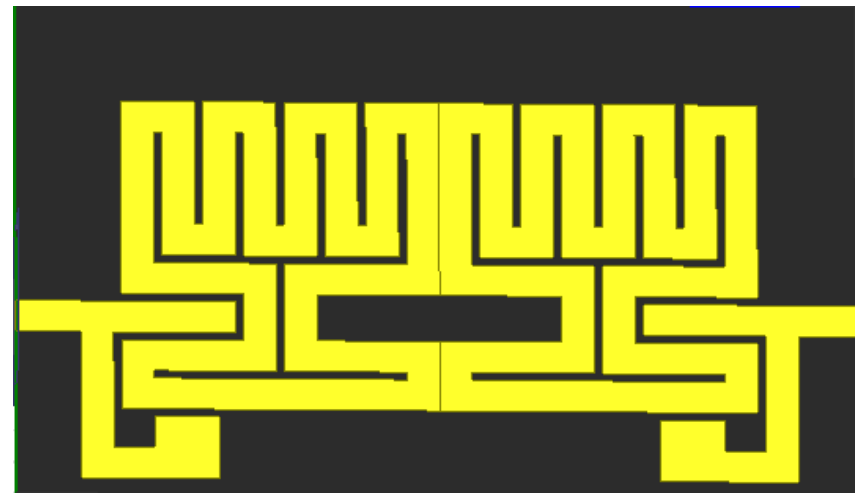

Fig 3 Band Pass Filter Using SIR

The frequency band covered by this filter is 5.67 to $6.12 \mathrm{GHz}$. It is shown in Fig 4. This can be used in WLAN applications. The center frequency of this filter is $5.95 \mathrm{GHz}$. This frequency is applicable in $802.11 \mathrm{p}$. $802.11 \mathrm{p}$ is also known as Wireless Access in Vehicular Environments (WAVE). It specifies WLAN for Intelligent Transportation System (ITS).

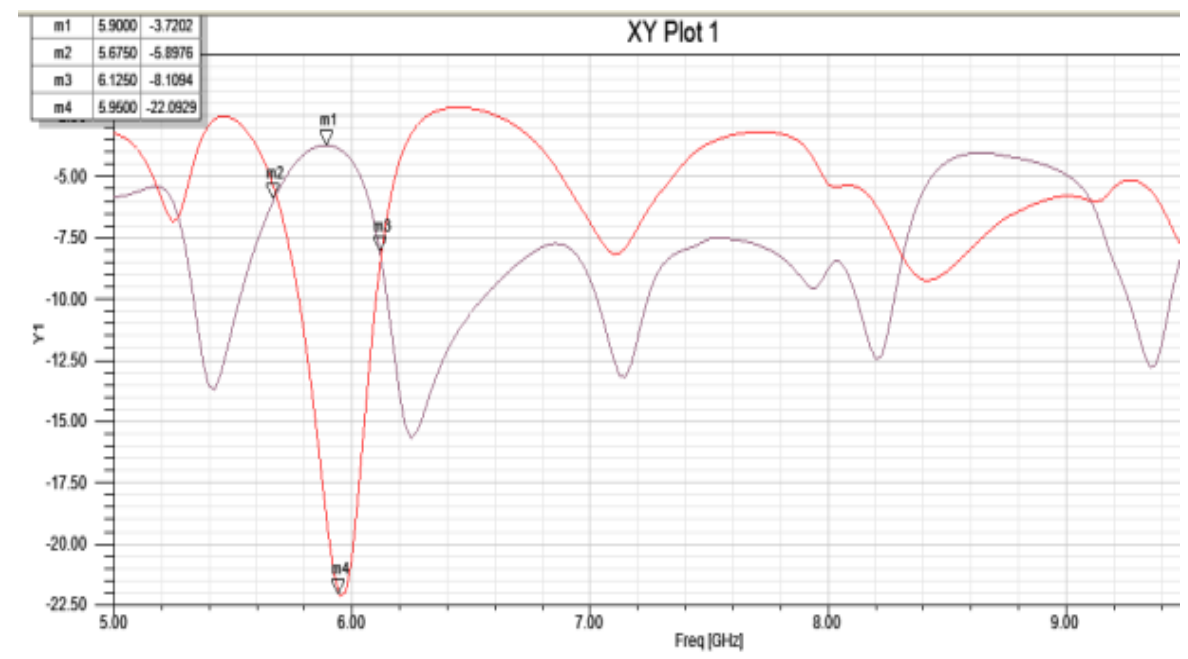

The insertion loss obtained in this filter is shown in Fig 5. The value of insertion loss is found to be $-3.72 \mathrm{~dB}$. Insertion loss can be defined as the loss of signal power resulting from the insertion of device in a transmission line or fiber optic cable. It is given by the ratio of power transmitted to the power received.

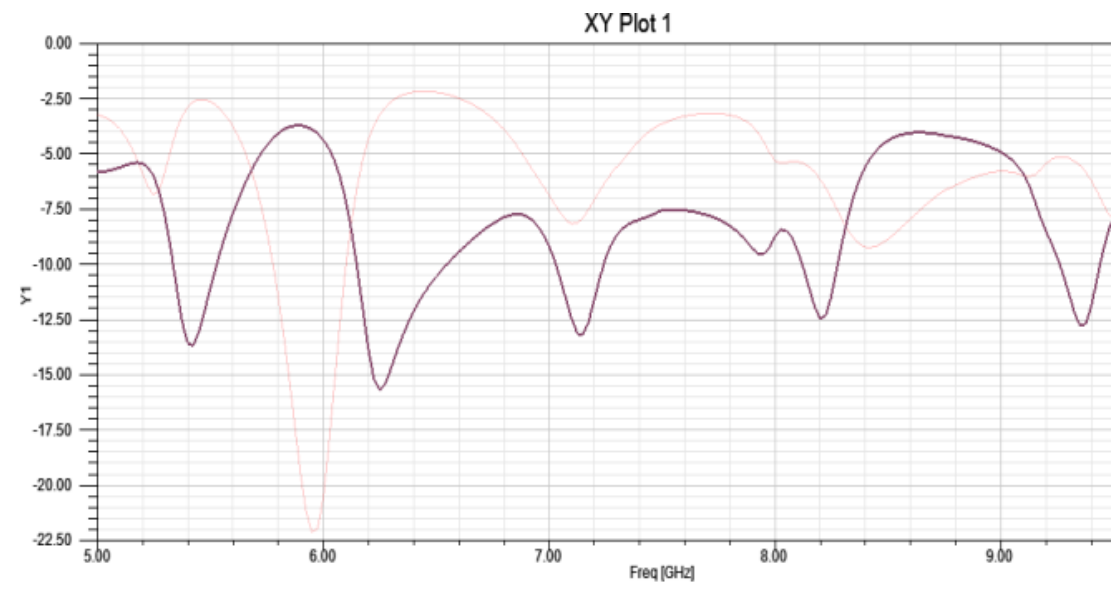

Fig 5 Insertion Loss for Band Pass Filter using SIR 


\title{
International Journal of Advanced Research in Computer and Communication Engineering
}

\author{
Vol. 8, Issue 5, May 2019
}

The return loss obtained in this filter is shown in Fig 6. The value of return loss obtained is given as $-22.09 \mathrm{~dB}$. Return loss is defined as the loss of power returned/reflected by a discontinuity in a transmission line or optical fiber. It is expressed in decibels and given as ratio between incident power and reflected power.

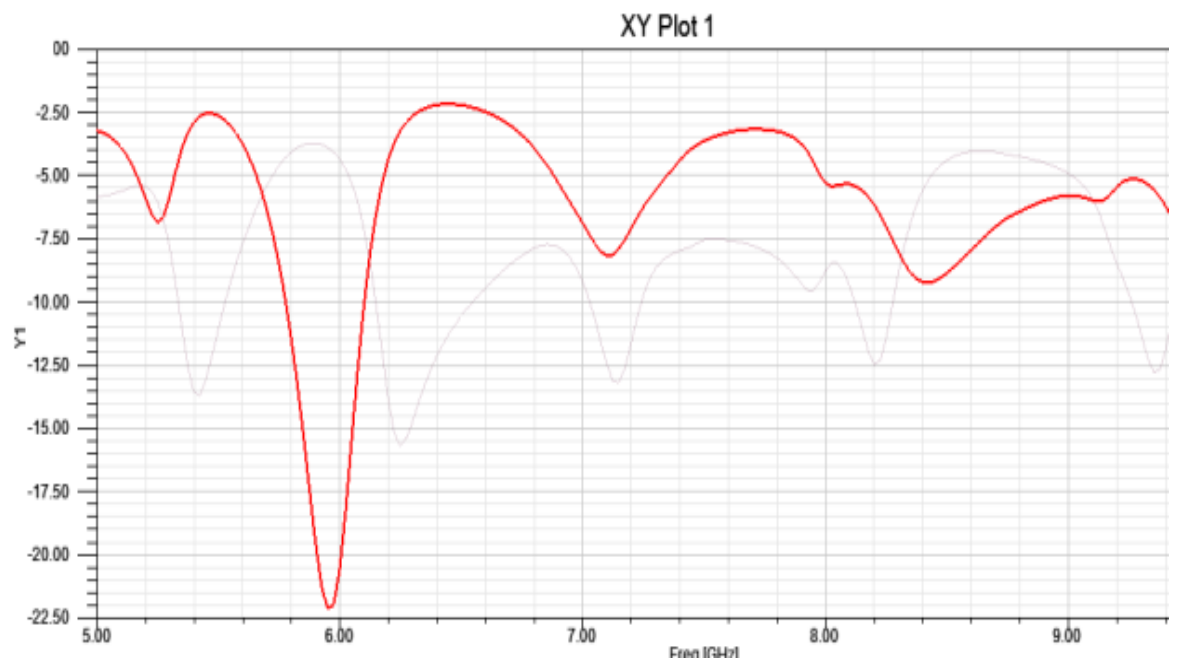

Fig 6 Return Loss for Band Pass Filter using SIR

\section{CONCLUSION}

The paper presented above describes a bandpass filter designed using meander structures and SIR. It is found that the SIR enhances return loss and the structure provides wideband coverage. The structure is simulated using High Frequency Structure Simulator (HFSS) and the filter operates at a frequency of 5.9GHz. This frequency is utilized for WLAN application specifically in vehicular communication systems. The electrical size of the filter is $30 \mathrm{x} 51.5 \mathrm{~mm}^{2} . \mathrm{It}$ offers good performance with effective return loss and insertion loss. The use of meander offers compact size and better current distribution properties over a wide passband.

\section{REFERENCES}

[1]. R Samson Daniel, R Pandeeswari, S. Raghavan(2018)“Dual- band monopole antenna loaded with ELC metamaterial resonator for WiMAX and WLAN applications" Applied Physics A, vol.124, issue18.

[2]. R.Samson Daniel,((2014) "Design and Simulation of Multiband CPW feed Ring Shaped Antenna for Wireless Applications" International Journal of Engineering Sciences \& Research Technology, pp.549-553.

[3]. N.ThamilSelvi, R. Pandeeswari, and P. N. ThiruvalarSelvan,(2018)"An Inset-Fed Rectangular Microstrip Patch Antenna with Multiple Split Ring Resonator Loading for WLAN and RF-ID Applications", PIER C, vol.81, pp.41-52.

[4]. N. ThamilSelvi, P. N. ThiruvalarSelvan, S. P. K. Babu, R.Pandeeswari, and R. Samson Daniel,(2018) "A Broad- Side Coupled SRR Inspired CPW Fed Dual Band Antenna for WiMAX and Wave Applications", PIER C vol. 80, pp.221 - 231.

[5]. Anil Kumar, B Murugeshwari, S Raghavan,(2018) "Design of Substrate Integrated Waveguide Power Divider and Parameter optimization using Neural Network", IOSR Journal of Electronics and Communication Engineering (IOSR-JECE), Vol.13, issue 1, PP 37-43.

[6].VarikuntlaKrushnakanth,B.Murugeshwari \&SingaraveluRaghavan,(2017) "Design of a CPW Fed Substrate integrated waveguide using Frequency selective surface" $11^{\text {th }}$ International Radar symposium, India ( IRSI'17), Bangalore,India.

[7]. Muruganantham T, Surendar U, Balakumar A(2017) "Dual Band Bandpass Filter With Sharp Passband Resonances Using Dual-Mode SIRs” International journal of microwave applications, volume 6, no.2.

[8]. Gayathri R, Maheswari M,(2017) "Design And Fabrication Of Dual Band RFID Antenna Using Hybrid Coupler With CSRR", Pakistan Journal of Bio Technology, Vol.14(1), pp. 87-89.

[9]. S.Monisha, U.Surendar,(2018) "A Survey on Wearable Antenna for ISM Band Application", IOSR Journal of Electronics and Communication Engineering, pp. 49-54.

[10]. S.Praveena, B.Murugeshwari, U.Surendar R.Kayalvizhi,(2018)“A Review on Antenna Design for Millimeter Wave range”, IOSR Journal of Electronics and Communication Engineering, pp. 01-06.

\section{BIOGRAPHIES}

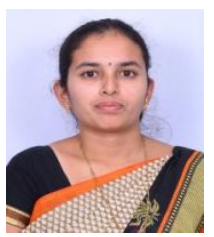

S.Rajapriya, Assistant Professor of Department of ECE in K.Ramakrishnan College of Engineering. She completed her B.E in ECE Department at Periyar Maniammai College of Technology for Women.She completed her M.Tech in Communication Systems at PRIST University.Her Research Interests are Antenna and wave propagation, Transmission lines \& Waveguides, RF \& Microwave engineering and Digital Image Processing. 


\section{International Journal of Advanced Research in Computer and Communication Engineering}

Vol. 8, Issue 5, May 2019

G.Gomathi, Assistant Professor of Department of ECE in K.Ramakrishnan College of Engineering.She completed her B.E in ECE Department at NPR College of Engineering and Technology.She completed her M.E in Communication Systems at RVS College of Engineering and Tecnology.Her Research Interests are Antenna and wave propagation,Computer Networks,Electronic Devices and Circuits .

T.Muruganantham, Assistant Professor of Department of ECE in K.Ramakrishnan College of Engineering.He completed his B.E in ECE Department at J.J.College of Engineering and Technology.He completed his M.E in Power Electronics at A.C.College of Engineering and Technology.His Research Interests are CMOS Based Low Noise Amplifier for efficient Transceiver. 